\title{
Halophytic Hordeum brevisubulatum HbHAK1 Facilitates Potassium Retention and Contributes to Salt Tolerance
}

\author{
Haiwen Zhang ${ }^{1}$, Wen Xiao ${ }^{1,2}$, Wenwen $\mathrm{Yu}^{1,2}$, Ying Jiang ${ }^{1}$ and Ruifen $\mathrm{Li}^{1, *}$ \\ 1 Beijing Key Laboratory of Agricultural Genetic Resources and Biotechnology, Beijing Agro-Biotechnology \\ Research Center, Beijing Academy of Agriculture and Forestry Sciences, Beijing 100097, China; \\ hwzhang0422@hotmail.com (H.Z.); xiaowen7821@163.com (W.X.); 18800109890@163.com (W.Y.); \\ jiangying198212@126.com (Y.J.) \\ 2 Beijing Key Laboratory of Plant Gene Resources and Biotechnology for Carbon Reduction and \\ Environmental Improvement, College of Life Sciences, Capital Normal University, Beijing 100048, China \\ * Correspondence: liruifen@aliyun.com; Tel.: +86-10-51503257
}

Received: 28 June 2020; Accepted: 20 July 2020; Published: 25 July 2020

\begin{abstract}
Potassium retention under saline conditions has emerged as an important determinant for salt tolerance in plants. Halophytic Hordeum brevisubulatum evolves better strategies to retain $\mathrm{K}^{+}$ to improve high-salt tolerance. Hence, uncovering $\mathrm{K}^{+}$-efficient uptake under salt stress is vital for understanding $\mathrm{K}^{+}$homeostasis. $\mathrm{HAK} / \mathrm{KUP} / \mathrm{KT}$ transporters play important roles in promoting $\mathrm{K}^{+}$ uptake during multiple stresses. Here, we obtained nine salt-induced HAK/KUP/KT members in $H$. brevisubulatum with different expression patterns compared with $H$. vulgare through transcriptomic analysis. One member $\mathrm{HbHAK} 1$ showed high-affinity $\mathrm{K}^{+}$transporter activity in athak5 to cope with low- $\mathrm{K}^{+}$or salt stresses. The expression of HbHAK1 in yeast Cy162 strains exhibited strong activities in $\mathrm{K}^{+}$uptake under extremely low external $\mathrm{K}^{+}$conditions and reducing $\mathrm{Na}^{+}$toxicity to maintain the survival of yeast cells under high-salt-stress. Comparing with the sequence of barley HvHAK1, we found that $\mathrm{C} 170$ and $\mathrm{R} 342$ in a conserved domain played pivotal roles in $\mathrm{K}^{+}$selectivity under extremely low- $\mathrm{K}^{+}$conditions $(10 \mu \mathrm{M})$ and that $\mathrm{A} 13$ was responsible for the salt tolerance. Our findings revealed the mechanism of $\mathrm{HbHAK} 1$ for $\mathrm{K}^{+}$accumulation and the significant natural adaptive sites for HAK1 activity, highlighting the potential value for crops to promote $\mathrm{K}^{+}$-uptake under stresses.
\end{abstract}

Keywords: $\mathrm{HAK} / \mathrm{KUP} / \mathrm{KT}$ transporter; $\mathrm{K}^{+}$-uptake; salt-tolerance; $\mathrm{K}^{+} / \mathrm{Na}^{+}$homeostasis; site mutation

\section{Introduction}

Potassium represents $2.6 \%$ of the weight of the Earth's crust. However, dissolved $\mathrm{K}$ in soil-as the only fraction directly available to plant-is deficient, especially in saline-alkali land and arid land [1]. Retaining potassium under stress conditions in plants has emerged as novel and essential mechanisms for plant survival $[2,3]$. Studying the mechanisms of highly efficient uptake of potassium from the soil in roots is critical for the growth and production of crops.

As ion fluxes control ion concentration, the HAK/KUP/KT (high affinity $\mathrm{K}^{+} / \mathrm{K}^{+}$uptake proteins $/ \mathrm{K}^{+}$ transporter) proteins function as $\mathrm{K}^{+}$-transporters and the major contributor for $\mathrm{K}^{+}$nutrition in $\mathrm{K}^{+}$ depleted soil [4]. This family is widespread in all of the plant kingdom; $913 \mathrm{HAK/KUP/KT} \mathrm{sequences}$ have been identified in 46 plant genomes, with an uneven distribution between dicotyledonous and monocotyledonous species [5]. The information available on crop genomes shows a richness of HAK/KUP/KT transporters (about 27 members) compared with dicotyledonous plants (13 members in Arabidopsis), which indicates the important physiological roles of such transporters in crops. Their proteins possess 10-15 transmembrane (TM) domains and are divided into 5 clusters [5]. Genes in 
cluster I are the most functionally revealed, including classical AtHAK5, HvHAK1, OsHAK1, OsHAK5, ThHAK1, SlHAK5, CcHAK1 and so on [6-12]. They all have a high-affinity $\mathrm{K}^{+}$transport feature that allows plant to thrive under low- $\mathrm{K}^{+}(<1 \mathrm{mM})$ conditions. In fact, $\mathrm{K}^{+}$uptake in plants also demands these HAK-type transporters under multiple stresses such as salinity, $\mathrm{Cs}^{+}$-polluted or drought soils [4]. One reason is that higher external $\mathrm{Na}^{+}, \mathrm{Cs}^{+}$or drought indirectly reduces soluble $\mathrm{K}^{+}$concentration in soil that leads to $\mathrm{K}^{+}$deficiency [13-15]. On the other hand, accumulations of $\mathrm{Na}^{+}$or $\mathrm{Cs}^{+}$in cells causes ion imbalances with a reduced $\mathrm{K}^{+} / \mathrm{Na}^{+}$or $\mathrm{K}^{+} / \mathrm{Cs}^{+}$ratio that inhibits plant growth $[16,17]$. In crops, the loss of OsHAK1 in rice leads to about $50-55 \%$ lower $\mathrm{K}^{+}$uptake than wild types in $\mathrm{K}$-starved environments, and causes sensitivity to drought and salt $[8,18]$. OsHAK1, OsHAK5, OsHAK16 and OsHAK21 can coordinately regulate $\mathrm{Na}^{+} / \mathrm{K}^{+}$homeostasis and the membrane potential of root cells under salt conditions $[4,8,9,18,19]$. A genome-wide association (GWAS) study in Zea mays L. showed ZmHAK4-mediated shoot $\mathrm{K}^{+} / \mathrm{Na}^{+}$homeostasis for improving salt tolerance, conferring the natural variation of this gene [20]. Therefore, under saline conditions, $\mathrm{K}^{+}$nutrition largely depends on HAK/KUP/KT system, affecting agriculture worldwide.

Saline land occupies more than $20 \%$ of irrigated soil. It reduces crop productivity because most crops are glycophytes [21]. As barley is the most salt-tolerant species among crops, several wild Hordeum species are halophytes [22,23]. Hordeum brevisubulatum is perennial among these halophytic species and could be used as a saline-tolerant grass for soil improvement in North China [24]. Our previous reports have shown its remarkable salt tolerance due to low $\mathrm{Na}^{+}$accumulation and stable $\mathrm{K}^{+}$content compared with barley [25,26]. Although the genome of H. brevisubulatum is unpublished, a transcriptomic analysis could provide clues for gene identification and understanding of salt-tolerance molecular mechanism. We extracted and identified $13 \mathrm{HAK} / \mathrm{KUP} / \mathrm{KT}$ members from salt-treated transcriptomic data. Because of the different expression patterns between these genes in $H$. vulgare and $H$. brevisubulatum, we focused on functional study of HbHAK1. As the genus Hordeum belongs to Triticeae, the sequences of its functional genes share many similar sequences with barley and wheat [26]. HbHAK1 showed better transport activity than barley HvHAK1, though only 15 amino acids residues were different between them. Based on the 15 amino acids, further studies revealed C170 and R342 conserved amino acids significantly involved in the $\mathrm{K}^{+}$selectivity and transport activity under extremely low- $\mathrm{K}^{+}$conditions $(10 \mu \mathrm{M})$, and $\mathrm{A} 13$ directly affect the $\mathrm{K}^{+}$uptake under high external $\mathrm{Na}^{+}$condition. Our study significantly revealed the natural adaptive sites of HbHAK1 were the key residues for improving HAK1-type activity, highlighting the potential value for crops to promote $\mathrm{K}^{+}$uptake under stresses.

\section{Results}

\subsection{HAK/KUP/KT Proteins Were Identified According to Transcriptomic Analysis}

Our previous reports revealed that $H$. brevisubulatum plants could maintain a relatively stable level of $\mathrm{K}^{+}$content under saline conditions and the numbers of upregulated genes of potassium transporters greatly exceeded that in $\mathrm{H}$. vulgare, which showed obvious $\mathrm{K}^{+}$loss under saline conditions [26]. As these large amounts of $\mathrm{K}$ are taken up from soil and then are re-translocated and cycled, we performed Illumina RNA sequencing (RNA-seq) on a time series $(0,1,6$ and $24 \mathrm{~h}$ ) of the roots of 21-day-old $H$. brevisubulatum and $H$. vulgare plants under $350 \mathrm{mM} \mathrm{NaCl}$ treatment. We searched the potential HAK/KUP/KT transporters in PacBio isoform sequencing (Iso-seq) data. Finally, 13 genes with intact coding DNA sequences were obtained and named following the homologous genes in rice and barley. These proteins contained about 708-945 amino acids and were predicted to contain 11-14 trans-membrane regions with a long tail in the C-terminal. All these proteins were localized in the plasma membrane, which were analyzed using TargetP tool (http://www.cbs.dtu.dk/services/TargetP/) (Table 1). Based on the alignment of these 13 proteins in $H$. brevisubulatum and the HAK/KUP/KT proteins in rice, a phylogenetic tree was constructed (Figure 1). HAK/KUP/KT members can be divided into 5 clusters, as crop genomes contains all the 5 clusters while the Arabidopsis has only 4 clusters [5]. 
The 13 proteins were localized in 4 clusters. No genes belonged to Cluster IV, in detail, as 4 in cluster I ( 8 in rice), 5 in cluster II (9 in rice), 3 in cluster III ( 3 in rice) and 1 in cluster V ( 3 in rice) (Figure 1 ).

Table 1. The list of 13 identified HAK/KUP/KT proteins in H. brevisubulatum.

\begin{tabular}{cccc}
\hline Gene & Protein Length & TMS $^{\mathbf{a}}$ & PL $^{\mathbf{b}}$ \\
\hline HbHAK1 & 776 & 12 & plasma membrane \\
HbHAK2 & 777 & 13 & plasma membrane \\
HbHAK5 & 708 & 11 & plasma membrane \\
HbHAK7 & 784 & 13 & plasma membrane \\
HbHAK8 & 789 & 12 & plasma membrane \\
HbHAK9 & 781 & 11 & plasma membrane \\
HbHAK11 & 792 & 14 & plasma membrane \\
HbHAK12 & 763 & 14 & plasma membrane \\
HbHAK16 & 799 & 11 & plasma membrane \\
HbHAK18 & 785 & 14 & plasma membrane \\
HbHAK23 & 945 & 12 & plasma membrane \\
HbHAK25 & 769 & 13 & plasma membrane \\
HbHAK27 & 874 & 12 & plasma membrane \\
\hline
\end{tabular}

a TMS: number of transmembrane segments posses; ${ }^{\mathrm{b}}$ Localization of HbHAKs protein supported by TargetP.

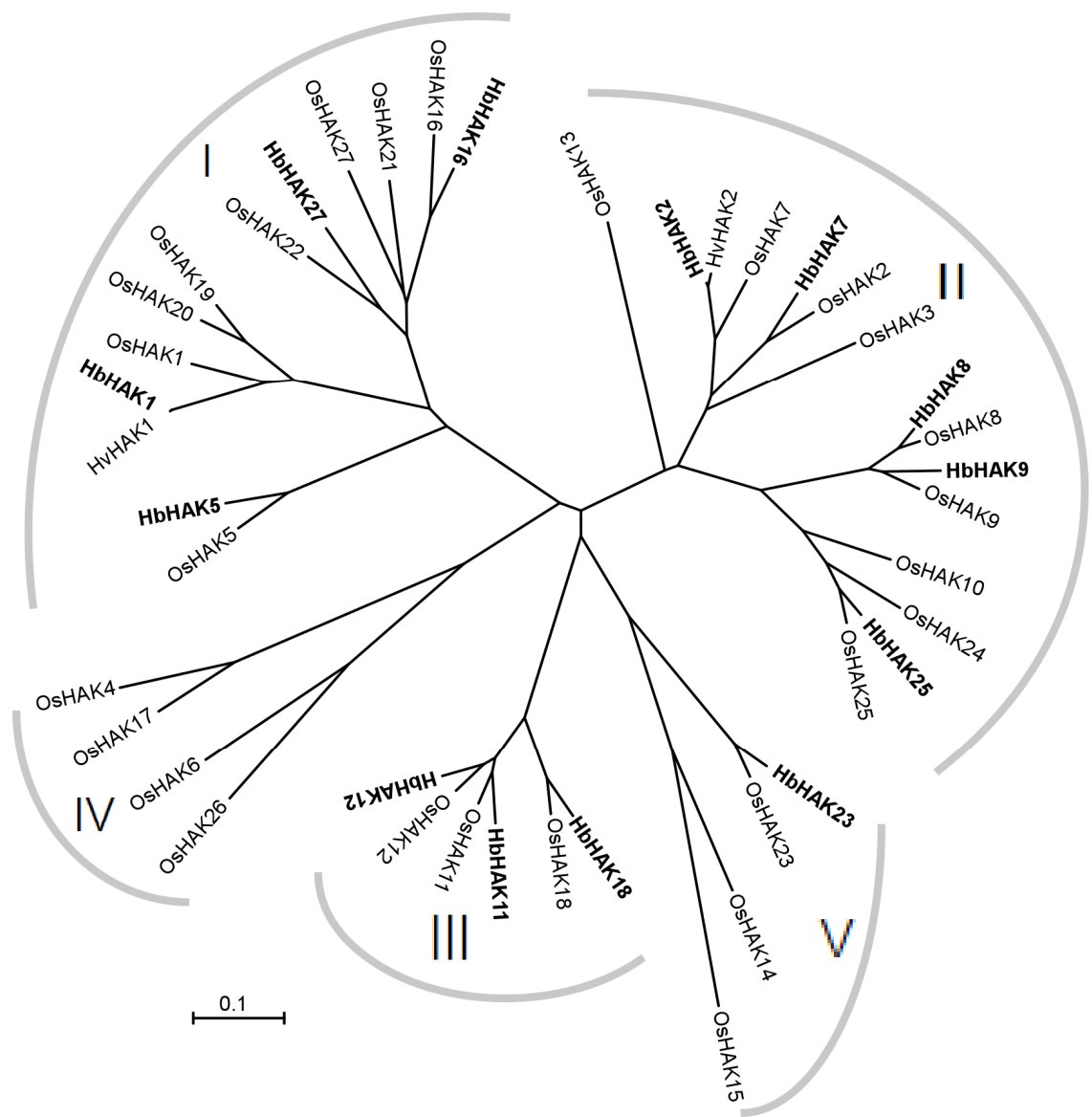

Figure 1. Phylogenetic relationships between identified HAK/KUP/KT proteins in H. brevisubulatum and all the HAK/KUP/KT proteins in rice. Phylogenetic tree was generated with MEG5.0 software (http: //www.megasoftware.net/) using the neighbor-joining method. The scale indicates the genetic distance.

\subsection{HbHAK1 Was Upregulated by Salt Stress in Roots with the Differential Expression Patterns}

In order to explore the mechanism of efficient $\mathrm{K}^{+}$uptake in $\mathrm{H}$. brevisubulatum, we extracted the expression information of 13 identified $\mathrm{HAK} / \mathrm{KUP} / \mathrm{KT}$ proteins from transcriptomic data of root tissues. 
The homologous genes coding these $13 \mathrm{HAK} / \mathrm{KUP} / \mathrm{KT}$ proteins in $\mathrm{H}$. vulgare from transcriptomic data were also extracted. Comparing these genes in $H$. brevisubulatum and $H$. vulgare, 9 members with different expression patterns were identified (Figure 2). Interestingly, $H$. brevisubulatum and $H$. vulgare showed the definitely opposite expression patterns in $H b H A K 1$ and $H b H A K 2$ under salt stress, as the HbHAK1 and $H b H A K 2$ were upregulated while the HvHAK1 and HvHAK2 were obviously negative-induced under high-salt conditions (Figure 2). Notably, HvHAK1 showed obvious downregulated expression pattern with about $85 \%$ lower than normal conditions after $6 \mathrm{~h}$ salt treatment, while the expression level of $H b H A K 1$ was stable-even $50 \%$ higher than normal conditions at the 24-h point. HbHAK1 and HvHAK1 all belonged to Cluster I subfamily. Many genes in this cluster are also involved in salt tolerance. Therefore, revealing HAK1-type $\mathrm{K}^{+}$transporters in halophytic plants may improve our knowledge of understanding $\mathrm{K}$ nutrition from soil under saline conditions.

\subsection{HbHAK1 Worked as a High-Affinity $K^{+}$Transporter on the Plasma Membrane and Involved in Salt Tolerance}

The Arabidopsis athak 5 mutant showed growth defects in the low- $\mathrm{K}^{+}$environment while the growth can be gradually recovered with the environmental $\mathrm{K}^{+}$content increasing [27]. Therefore, we developed the fusion construct $H b H A K 1::$ GFP under the control of CaMV $35 S$ promoter and transformed it into athak5. The HbHAK1 transcription was detected in the transgenic lines of athak5 (Figure 3A). As shown in Figure 3B, GFP fluorescence on the epidermal cells of leaves in transgenic lines was particularly observed on the plasma membrane, coinciding well with the fluorescence of FM4-64 stain (Figure 3B).
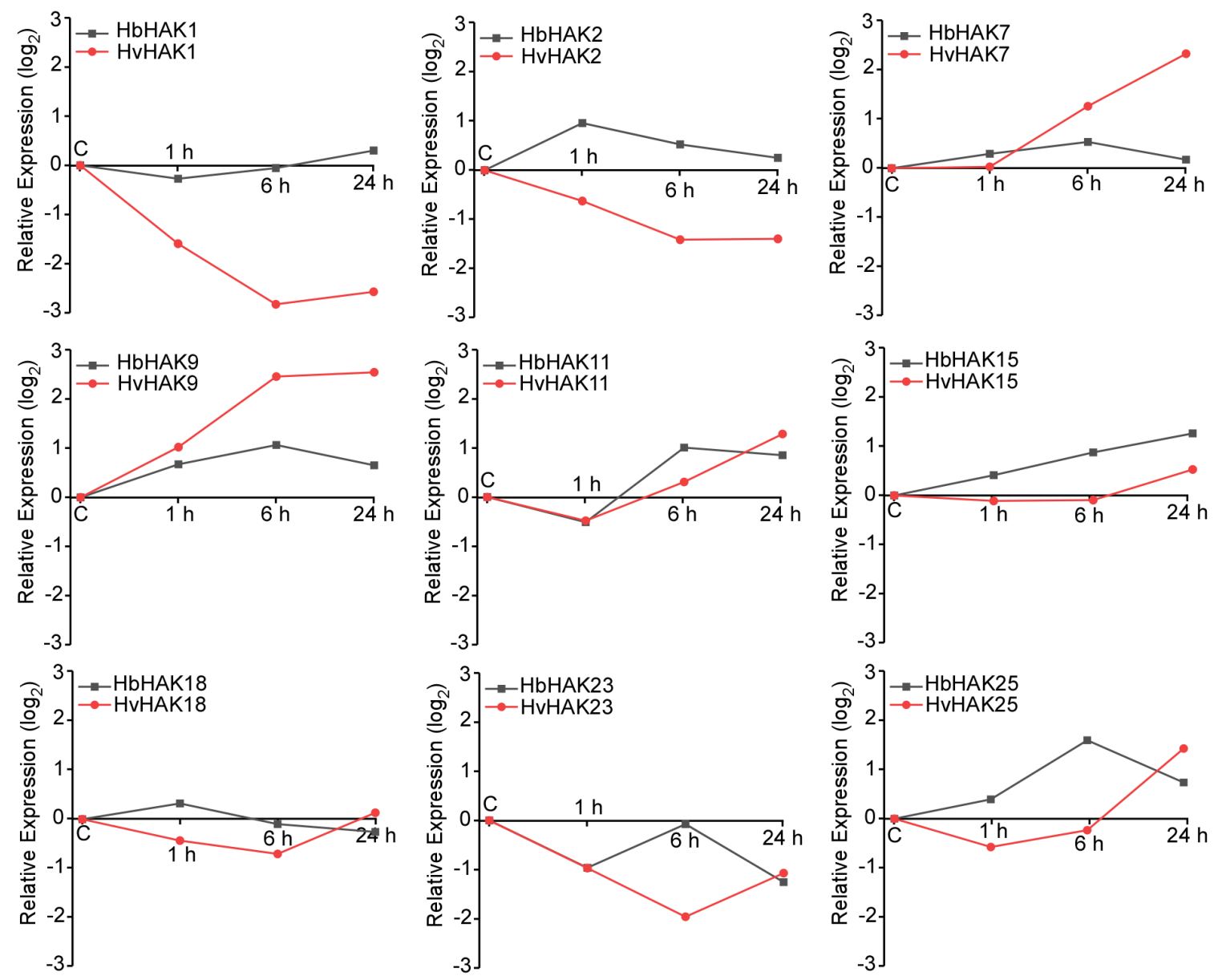

Figure 2. Selected HAK/KUP/KT genes with different expression pattern from barley. The expression level in different time course was compared with no- $\mathrm{NaCl}$ treatment control. The data were using a criterion of absolute log2(fold-change) of the relative expression levels. 
To examine the function of HbHAK1, we selected two transgenic lines in the athak 5 mutant background to access the growth of plants under low- $\mathrm{K}^{+}$conditions or high-salt conditions. The athak 5 mutants showed severe growth defect on MP medium without $\mathrm{K}^{+}$added, including root growth and cotyledon development, however, the expression of $H b H A K 1$ was obviously rescued this phenotype, performing the same growth as wild type (Figure $3 \mathrm{C}$ ). With the external $\mathrm{K}^{+}$content increasing, the growth of athak 5 was recovered, and this phenotype gradually became indistinguishable from transgenic lines and wild type. The root length and fresh weight of athak5 were at the same level with transgenic lines (Figure 3D) when the external $\mathrm{K}^{+}$content was up to $100 \mu \mathrm{M}$. The rescued phenotype confirmed the function of $\mathrm{HbHAK} 1$ as a high-affinity $\mathrm{K}^{+}$transporter mediating $\mathrm{K}^{+}$uptake under low- $\mathrm{K}^{+}$environment.

Under salt condition, the accumulation of $\mathrm{Na}^{+}$in root cells can depolarize plasma membrane and reduce the driving force for $\mathrm{K}^{+}$uptake. In order to access whether HbHAK1 contributes to salt tolerance, we transferred 3-day-old seedlings of wild type, two HbHAK1 transgenic lines in athak5 and athak5-mutant to plates with different $\mathrm{NaCl}$ content treatment for another 7 days. The two transgenic lines showed better growth under salt conditions than athak5 and wild type, especially under $100 \mathrm{mM}$ $\mathrm{NaCl}$ (Figure 4A). This was further evaluated by measuring the length of primary roots and the fresh weight of plants. Under high-salt conditions, the primary root lengths of HbHAK1 transgenic lines were obviously longer than wildtype, indicating HbHAK1 can mediate salt tolerance of plants (Figure 4B). The results suggested the improvement of salt tolerance of Arabidopsis plants via the expression of $H b H A K 1$, possibly depended on enhancing $\mathrm{K}^{+}$uptake under high $\mathrm{Na}^{+}$environment that lead to $\mathrm{K}^{+}$deficiency.

A

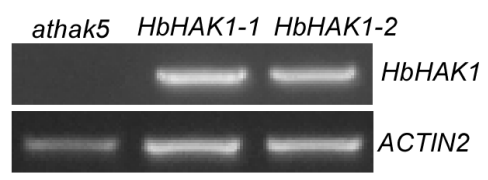

B
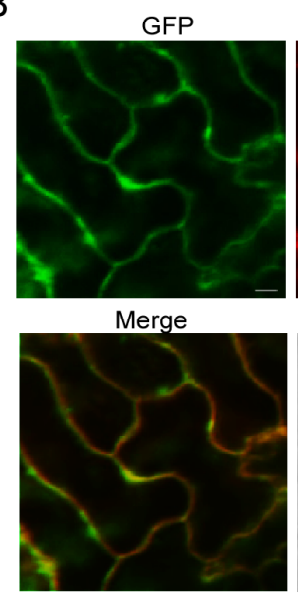

FM4-64

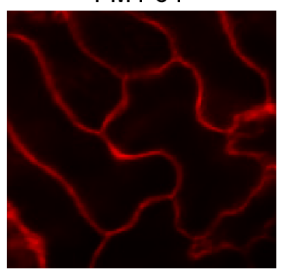

Bright field

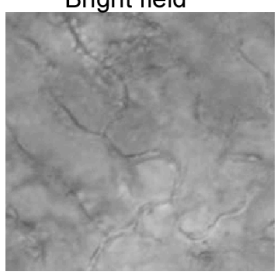

C
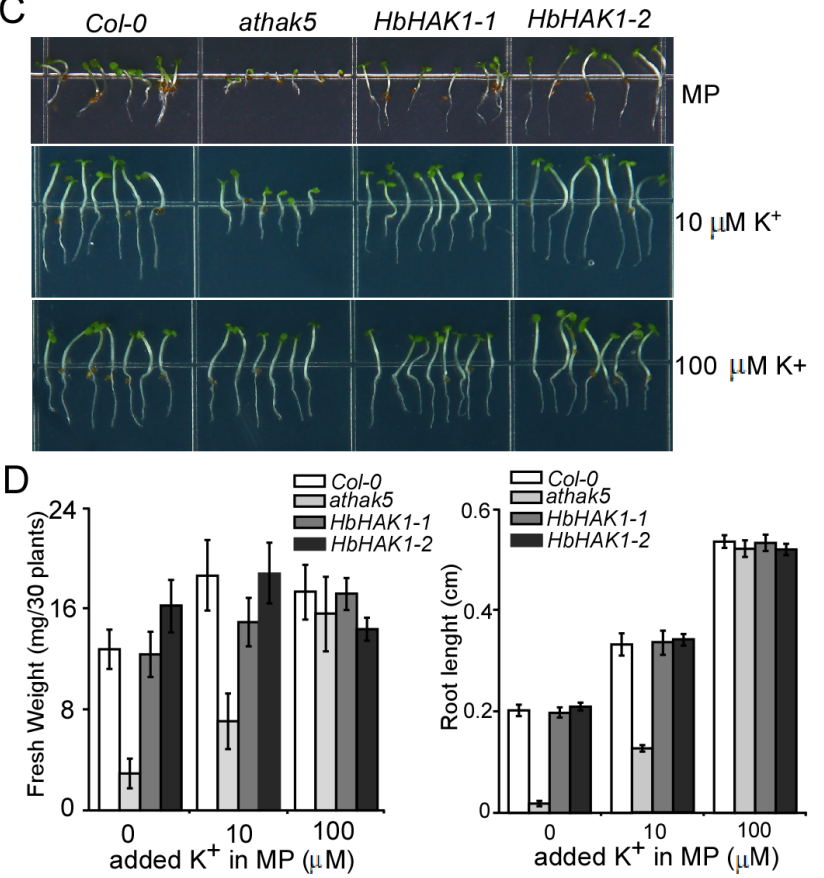

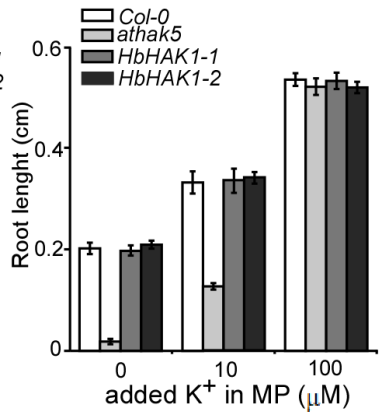

Figure 3. The expression of $H b H A K 1$ rescued the growth inhibition of athak5 under low- $\mathrm{K}^{+}$condition. (A) RT-PCR analysis of the HbHAK1 mRNA level in athak5 and two HbHAK1 transgenic lines (HbHAK1-1, HbHAK1-2); (B) Leaf epidermal cells in transgenic athak5 plants expressed HbHAK1-GFP. The GFP signal (green) is on the top left; the plasma membrane stained with FM4-64 (red) is on the top right; a merge (green and red) is on the bottom left; the bright field microscope image is on the bottom right. Scale bar $=20 \mu \mathrm{m}$; (C) The wild type, athak5, and two HbHAK1-GFP transgenic lines in athak5 (HbHAK1-1, HbHAK1-2) were grown for 7 days on MP medium with various $\mathrm{K}^{+}$added; (D) Fresh weight and root length of plants in (A). Each bar represents the mean fresh weight $(n=3)$ of 30 seedlings, and the mean root length of 30 seedlings from three independent experiments. The data represent the mean $\pm \mathrm{SD}$. 
To identify the hypothesis of $\mathrm{K}^{+}$uptake by HbHAK1, we introduced HbHAK1 and HbHAK2 into the yeast Cy162 strains. The Cy162 trk1 $\triangle$ trk $2 \Delta$ strains with loss of Trk1 and Trk2 potassium transporters is a perfect system for complementation study [28]. Drop serial dilutions of each strain were cultured on plates in AP-T medium with various $\mathrm{K}^{+}$added and images were captured after 2-3 days growth. When the external $\mathrm{K}^{+}$content was only $10 \mu \mathrm{M}, \mathrm{HbHAK} 1$ transformed strains could grow well even at $10^{-3}$ dilution while $H b H A K 2$ and empty vector transformants were unable to grow. The growths of all the strains were similar at the $5 \mathrm{mM} \mathrm{K}^{+}$content (Figure 5A). Growth curves of the yeast cells in liquid Ap-T medium at different $\mathrm{K}^{+}$concentrations further demonstrated the growth capacity of the $H b H A K 1$ transformed strains. At $50 \mu \mathrm{M} \mathrm{K}^{+}$content, the strains expressing HbHAK1 can grow well and the $\mathrm{OD}_{600}$ was up to $1.8 \mathrm{in} 60 \mathrm{~h}$, however, the $\mathrm{OD}_{600}$ of $\mathrm{HbHAK2}$ and empty vector transformed strains were still at a low level after $72 \mathrm{~h}$ (Figure $5 \mathrm{~B}$ ). When the added $\mathrm{K}^{+}$was reached to $2 \mathrm{mM}$, the HbHAK1 transformed strains were strongly growing and the $\mathrm{OD}_{600}$ was at 2.0 within $30 \mathrm{~h}$, meanwhile, the $\mathrm{OD}_{600}$ of $H b H A K 2$ transformants was still staying at 1.0 after $48 \mathrm{~h}$ (Figure 5C). For the kinetic study of HbHAK1 transporter, we carried out testing medium $\mathrm{K}^{+}$depletion experiment. Under the AP-T medium with $30 \mu \mathrm{M} \mathrm{K}^{+}$content, Cy162 cells expressing HbHAK1 showed rapid $\mathrm{K}^{+}$depletion in 20 min, indicating the rapid $\mathrm{K}$ absorption by HbHAK1, however, no depletion was observed in Cy162-HbHAK2 and empty vector transformants (Figure 5D). These results significantly identified the $\mathrm{K}^{+}$uptake function of $\mathrm{HbHAK} 1$ under extremely low- $\mathrm{K}^{+}$conditions.
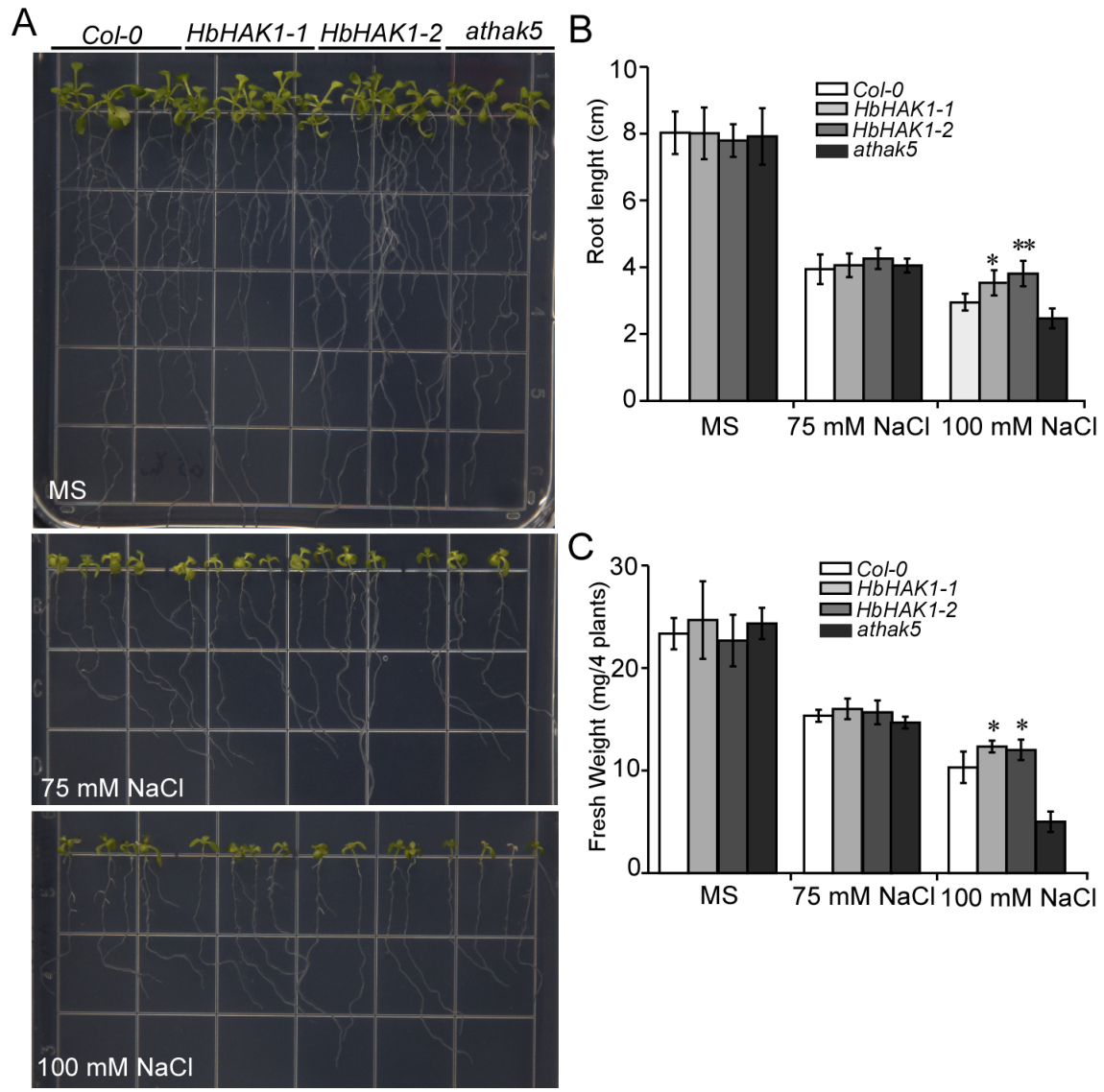

Figure 4. Expression of $H b H A K 1$ improved the salt tolerance of plants. (A) Wild type, two HbHAK1-GFP transgenic lines in athak5 (HbHAK1-1 and HbHAK1-2) and athak5 grown for 7 days on MS medium and then transferred MS with high $\mathrm{NaCl}$ concentration for another 7 days growth; $(\mathbf{B}, \mathbf{C})$ root length $(\mathbf{B})$ and fresh weight (C) of plants in (A). Each bar represents the mean root length of 30 seedlings from three independent experiments in $(\mathbf{B})$, and the mean fresh weight $(n=3)$ of 4 seedlings in $(\mathbf{C})$. Data represent mean \pm SD; Student's $t$-test was used to identify significant differences at the $p<0.05\left(^{*}\right)$ and $p<0.01$ $(* *)$ level. 


\subsection{HbHAK1 Strongly Mediated $\mathrm{K}^{+}$Uptake Under Low- $\mathrm{K}^{+}$Conditions or High $\mathrm{Na}^{+}$Condition}

To test the $\mathrm{Na}^{+}$influence on $\mathrm{HbHAK} 1$, we performed drop serial dilutions experiments in Cy162 system under $5 \mathrm{mM} \mathrm{K}^{+}$conditions with series of gradient $\mathrm{Na}^{+}$added. The results showed that the growth of empty vector transformed strains was obviously inhibited by external $\mathrm{Na}^{+}$added, however, HbHAK1 transformants still had better performance under $\mathrm{Na}^{+}$treatment, even at $750 \mathrm{mM} \mathrm{Na}{ }^{+}$ conditions which caused the failed growth of empty vector transformed strains (Figure 5E). To test whether $\mathrm{Na}^{+}$was also the substrate of HbHAK1, we introduced HbHAK1 into B31 ena1-4 $\triangle$ nha1 $\triangle$ yeast strain in which $\mathrm{Na}^{+}$export pumps are disrupted. AtHAK5 worked as a control (Figure S1). The B31 strain transformed HbHAK1 showed better growth than AtHAK5 and empty vector under $5 \mathrm{mM} \mathrm{K}^{+}$, however, when $50 \mathrm{mM} \mathrm{Na}^{+}$was added, all the strains exhibited salt sensitivity, suggesting $\mathrm{HbHAK} 1$ is not responsible for transporting $\mathrm{Na}^{+}$out of cells. We further tested the effect of $\mathrm{Cs}^{+}$on HbHAK1 and transferred to $20 \mathrm{mMCs}^{+}$and $20 \mathrm{mM} \mathrm{NH}_{4}{ }^{+}$added plates under $5 \mathrm{mM} \mathrm{K}^{+}$(Figure S2). The result showed the $\mathrm{K}^{+}$transport activity of $\mathrm{HbHAK} 1$ was greatly inhibited by $\mathrm{Cs}^{+}$or $\mathrm{NH}_{4}{ }^{+}$. Therefore, the experiments in Cy162 system indicated the intense $\mathrm{K}^{+}$transport activity of HbHAK1 from extremely low- $\mathrm{K}^{+}$ conditions and its strong $\mathrm{K}^{+}$uptake promoted the improvement of salt tolerance; however, it has no effect on reducing $\mathrm{Cs}^{+}$toxicity.

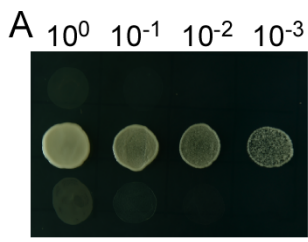

$10 \mu \mathrm{M} \mathrm{K}^{+}$

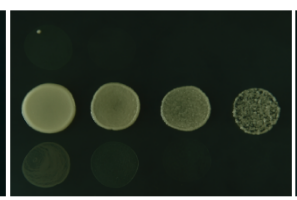

$100 \mu \mathrm{M} \mathrm{K}^{+}$

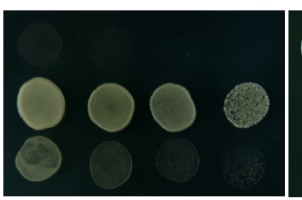

$1 \mathrm{mM} \mathrm{K}^{+}$

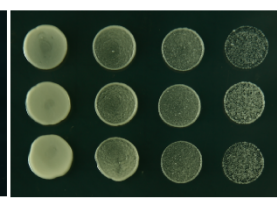

$10 \mathrm{mM} \mathrm{K}^{+}$

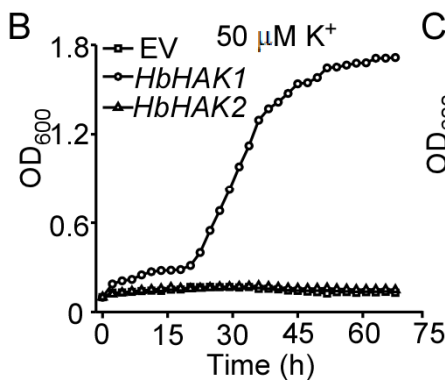

$\mathrm{E}$

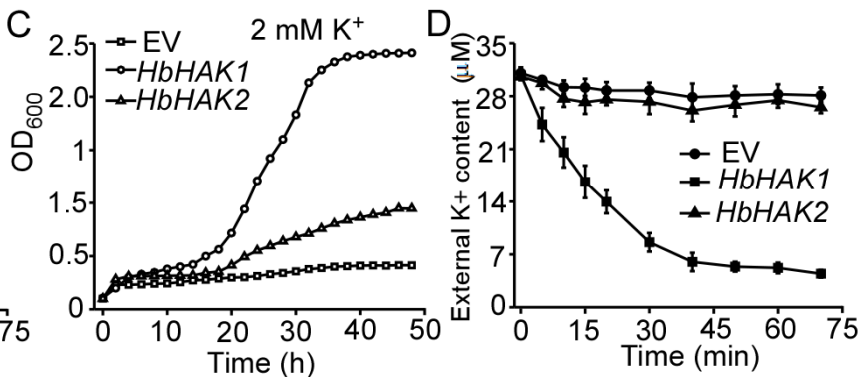

$\begin{array}{llll}10^{0} & 10^{-1} & 10^{-2} & 10^{-3}\end{array}$

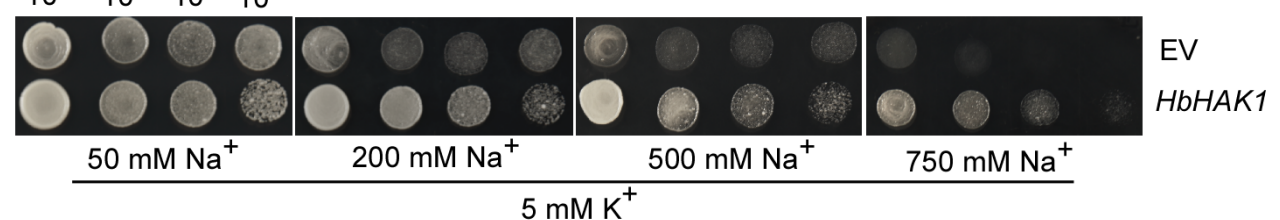

Figure 5. HbHAK1 and HbHAK2 complementation assays in yeast Cyl62 stains. (A) Growth of the Cy162 strains with p424 (empty vector), p424-HbHAK1 or p424-HbHAK2 transformed in solid AP-T medium with various $\mathrm{K}^{+}$concentrations. Drop serial dilutions of each strains were cultured on agar plates; (B,C) growth curves of the Cy162 strains transformed with p424, p424-HbHAK1 or p424-HbHAK2 in liquid AP-T medium with $50 \mu \mathrm{M} \mathrm{K}^{+}(\mathbf{B})$ or $1 \mathrm{mM} \mathrm{K}^{+}$(C) added; (D) $\mathrm{K}^{+}$-depletion experiment in the presence of $30-\mu \mathrm{M} \mathrm{K}^{+}$in liquid AP-T medium. The Cy162 strains transformed with p424, p424-HbHAK1 or p424-HbHAK2 were subjected to $\mathrm{K}^{+}$starvation for $4 \mathrm{~h}$ prior to the beginning of the experiment. The $\mathrm{K}^{+}$ content in the buffer was measured at intervals over a $2 \mathrm{~h}$ period. Three independent experiments were carried out and the data represent the mean $\pm \mathrm{SD}$; (E) growth of Cy162 strains transformed with p424 and p424-HbHAK1 in solid AP-T medium with various $\mathrm{Na}^{+}$concentrations under $10 \mathrm{mM} \mathrm{K}^{+}$. 
2.5. The Amino Acid Residues C170 and R342 of HbHAK1 Determined the Stronger Transport Activity in Low- $K^{+}$Conditions While A13 Under Salt Stress

To compare the transport activity of HbHAK1 with other homologs, we carried out complementation experiment in Cy162 strains transformed with HbHAK1, HvHAK1, OsHAK1 and AtHAK5. Drop serial dilutions of each strain were cultured on plates in AP-T medium with various $\mathrm{K}^{+}$added and images were captured after 2-3 days growth. The HbHAK1 transformants showed to grow well even at the $10^{-3}$ dilution under external $10 \mu \mathrm{M} \mathrm{K}^{+}$concentration, while the HvHAK1, OsHAK1 and AtHAK5 transformed strains were unable to grow. The HvHAK1 transformants grew at $100 \mu \mathrm{M} \mathrm{K}^{+}$content, and AtHAK5-expressing strains began to grow at $300 \mu \mathrm{M} \mathrm{K}^{+}$content (Figure $6 \mathrm{~A}$ ). These results confirmed that $\mathrm{HbHAK} 1$ had stronger $\mathrm{K}^{+}$transport activity.

Due to the close relationship between $H$. vulgare and $H$. brevisubulatum, we compared the sequences of amino acids between HbHAK1 and HvHAK1 and found that only 15 amino acids were different. To test whether the 15 amino acids affect the transport activity, we carried out site-directed mutation experiment to change each amino acid of HbHAK1 to that of HvHAK1. Colonies transformed with each mutant of HbHAK1 growing in SD-T selective media were transferred to plates with AP-T medium with different $\mathrm{K}^{+}$added. Drop complementation assays were performed to identify the activity of $\mathrm{K}^{+}$transport. Based on the transporter activity analysis, the mutants of A13T, C170A and R342K were selected. Many HAK1-type proteins in monocotyledonous species with genome published and AtHAK5 in Arabidopsis were used to run ClustalW alignment. Notably, the conserved site A170 in cytoplasmic loop in the other species was changed to C170 in HbHAK1, meantime conserved K342 in the seventh transmembrane domain was instead of R342 in HbHAK1 (Figure 6B). Colonies transformed with WT HbHAK1 could grow well under low- $\mathrm{K}^{+}$conditions $(10 \mu \mathrm{M})$, however, $\mathrm{C} 170 \mathrm{~A}$ or R342K single mutant transformed strains became unable to grow (Figure 6C). R342K transformants gradually recovered to grow until the $\mathrm{K}^{+}$content was above $100 \mu \mathrm{M}$ which showed the similar growth with HvHAK1, while C170A transformants were able to grow until the $\mathrm{K}^{+}$concentration was to $300 \mu \mathrm{M}$ (Figure 6C). A13 was in N-terminal of HbHAK1 and the A13T mutant transformed strain showed greatly similar performance with WT HbHAK1, however, with external $\mathrm{Na}^{+}$increasing, the A13T transformants exhibited weaker growth compared with WT HbHAK1 transformants (Figure 6C,D). The results revealed the importance of the amino acid residues of C170 and R342 for determining $\mathrm{K}^{+}$ selecting and transport activity under extremely low- $\mathrm{K}^{+}$conditions, the residue of A13 for enhancing $\mathrm{K}^{+}$uptake under high-salt conditions to improve salt tolerance. Because HbHAK1 was from the wild species of $H$. vulgare, its critical selected amino acid sites provided evidences that these significant natural variant sites may function as the stronger $\mathrm{K}^{+}$transport activity for HbHAK1, implying the key roles of these residues for the function-structure relationship studies of HAK1-type $\mathrm{K}^{+}$transporters. 
A

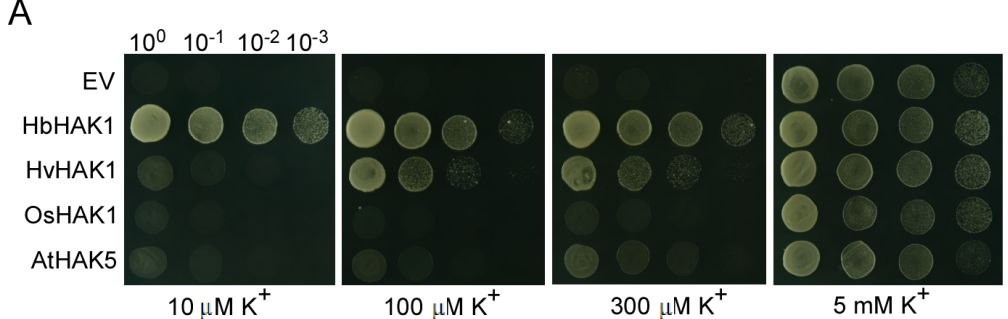

B
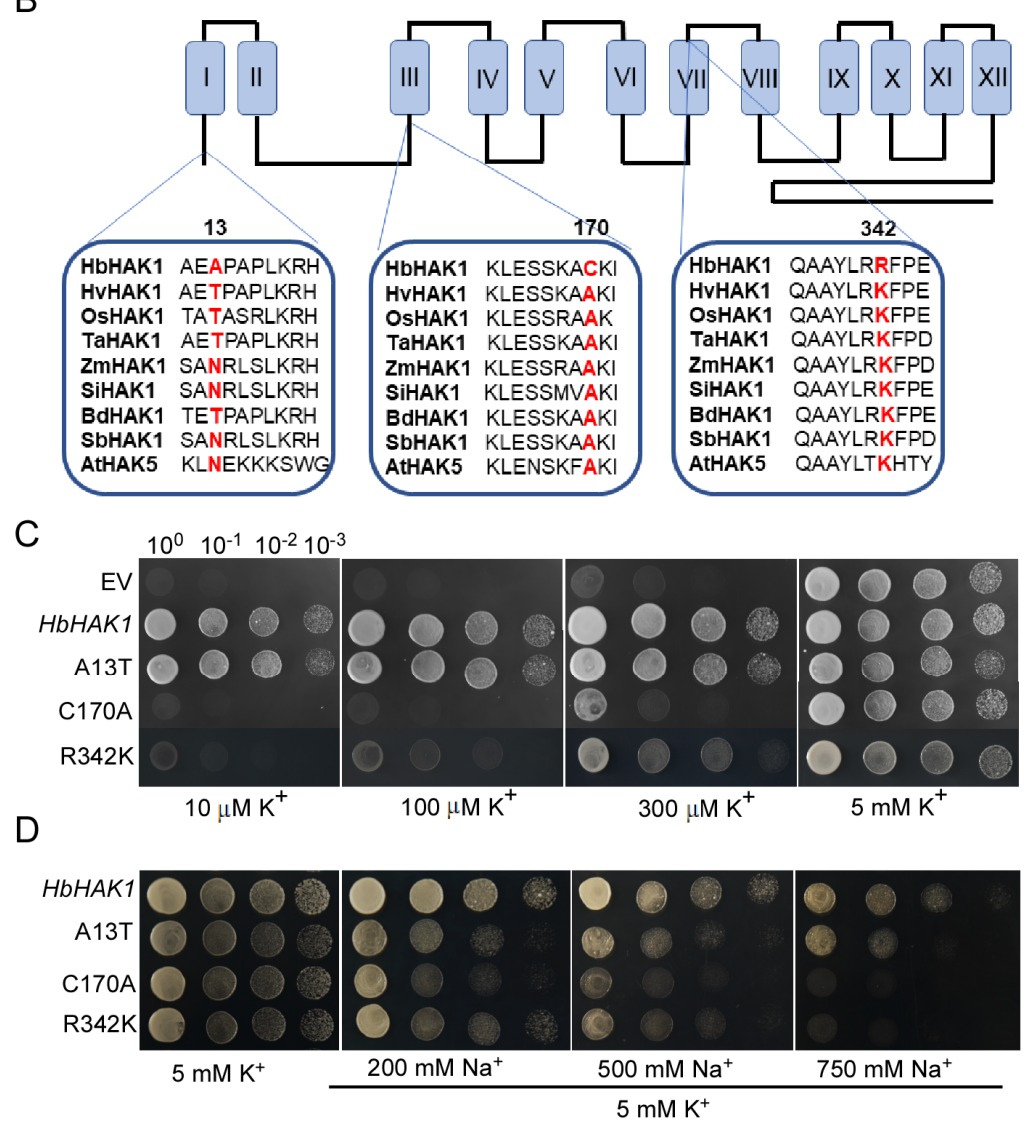

Figure 6. Main amino acids of HbHAK1 affected the transport activity. (A) Growth of Cy162 strains transformed with p424, p424-HbHAK1, p424-HvHAK1, p424-OsHAK1 and p424-AtHAK5 in solid AP-T medium with various $\mathrm{K}^{+}$concentrations; (B) HbHAK1 topology and the location of three significant amino acid. The proposed model for HbHAK1 protein is shown with 12 transmembrane domains and a long tail in C-terminal. The A13 residue is located in N-terminal. The C170 is located between the second and the third transmembrane domain. The R342 is located in the seventh transmembrane domain; (C) growth of Cy162 strains transformed with WT HbHAK1 and the mutants A13T, C170A and R342K in solid AP-T medium with various $\mathrm{K}^{+}$concentrations; (D) growth of Cy162 strains transformed with WT HbHAK1 and the mutants A13T, C170A and R342K in solid AP-T medium with various Na+ concentrations under $5 \mathrm{mM} \mathrm{KCl}$.

\section{Discussion}

$\mathrm{K}^{+}$acquisition in plant roots consists of two uptake systems: a high-affinity transporter system (HATS) via $\mathrm{H}^{+} / \mathrm{K}^{+}$symports at low $(<0.2 \mathrm{mM})$ external $\mathrm{K}^{+}$content and a low-affinity system (LATS) via ion channels at high $(>0.5 \mathrm{mM})$ external $\mathrm{K}^{+}$content. High-salt soil frequently causes $\mathrm{K}^{+}$deficiency, therefore, the HATS in roots dominates $\mathrm{K}^{+}$uptake from soil under saline conditions to maintain a stable cytosol $\mathrm{K}^{+}$concentration $(100-150 \mathrm{mM})$ [4,29]. Since the identification of HvHAK1 in barley [7] and AtHAK5 in Arabidopsis [30], HATS is considered to be operated by HAK/KUP/KT transporters [4]. 
AtHAK5 plays a pivotal role in maintaining high-affinity $\mathrm{K}+$ uptake under saline conditions [31], while different Cluster I members of HAK/KUP/KT family like OsHAK1, OsHAK5 and OsHAK21 coordinately contribute to high-affinity $\mathrm{K}^{+}$transport in $\mathrm{K}^{+} / \mathrm{Na}^{+}$homeostasis under salt $[4,8,9,19]$. To survive under saline conditions for plants, maintaining continuous $\mathrm{K}^{+}$acquisition at high external $\mathrm{Na}^{+}$content is crucial for $\mathrm{K}^{+} / \mathrm{Na}^{+}$homeostasis. The halophytic $H$. brevisubulatum could grow well under heavy saline-alkali land and be used as a saline-tolerant grass for soil improvement in North China [26,32], implying that the H. brevisubulatum plant may evolve some distinctive strategies for $\mathrm{K}^{+}$ acquisition improvement under saline conditions. The hypothesis was supported by the salt-treated root transcriptome data which showed abundant genes related to potassium ion transport were upregulated [26]. Among these genes, HAK-type transporters were obviously selected, in accordance with the root HATS operating $\mathrm{K}^{+}$uptake under saline conditions.

Through comparing the expression patterns of HAK/KUP/KT proteins between $H$. brevisubulatum and $H$. vulgare, the expression of HbHAK1 was induced by salt while transcripts of HvHAK1 was greatly downregulated (Figure 2). We further identified the function of HbHAK1 as a high-affinity $\mathrm{K}^{+}$ transporter via rescuing the phenotype of athak 5 in plant growth and salt tolerance (Figures 3 and 4 ). $\mathrm{HAK} / \mathrm{KUP} / \mathrm{KT}$ transporters could not generate $\mathrm{K}^{+}$currents in cells, thus, their function studies mainly carried out in yeast or bacteria mutants defective for $\mathrm{K}^{+}$uptake like yeast Cy162 strains. Interestingly, the $\mathrm{HbHAK} 1$ transformants can grow in the presence of extremely low external $\mathrm{K}^{+}(10 \mu \mathrm{M})$, as the same experiments confirm HvHAK1, OsHAK5, CcHAK1 and CaHAK1 transformants recover the growth at $0.1-\mathrm{mM} \mathrm{K}^{+}$added $[12,33,34]$ and OsHAK1 or AtHAK5 expressing strains can grow at $0.3-\mathrm{mM}$ external $\mathrm{K}^{+}$content $[8,10]$. The best performance of HbHAK1 in complementation of Cy162 strains indicated its strong $\mathrm{K}^{+}$transport activity and extended the minimum threshold of $\mathrm{K}^{+}$uptake operated by HAK-type transporters.

In fact, because of closed relationship between H. brevisubulatum and barley, HbHAK1 and HvHAK1 have only 15 different amino acid residues. We used site-directed mutations in cDNA of HbHAK1 and identified the transport activity of mutants HbHAK1 in Cy162 system. C170A and R342K mutant transformants critically reduced the capacity of strains growth under $10 \mu \mathrm{M} \mathrm{K}^{+}$conditions which showed even weaker growth compared with HvHAK1 at $0.1 \mathrm{mM} \mathrm{K}^{+}$and $0.3^{+} \mathrm{mM} \mathrm{K}^{+}$added, while A13T mutants dramatically decrease $\mathrm{Na}^{+}$tolerance (Figure 6). $\mathrm{C} 170$ and R342 were located at the strictly conserved region of Cluster I proteins in crop species and Arabidopsis, which indicated $\mathrm{C} 170$ and $\mathrm{R} 342$ were located in the core region for $\mathrm{K}^{+}$selectivity (Figure 6). The other identified $\mathrm{K}^{+}$ transporter families, such as Shaker channels, KOC channels and HKT transporters, are in charge of putative pore forming region from an ancestor submit of $\mathrm{K}^{+}$channel based on the research about $\mathrm{K}^{+}$ channel in animals, which is present in all $\mathrm{K}^{+}$channels among all the kingdom [35-38]. This region favored the structure-function relationship studies of these $\mathrm{K}^{+}$transporters and deep analysis of their transport activities. However, no such conserved pore forming region is in HAK transporters and HAK-type transporters are absent in animal kingdom, so structure-function relationship studies on HAK family proteins are almost unexplored field and identification of function domain is an interesting work. All previous researches used either random mutagenic PCR or the occurrence of spontaneous mutation of DNA to link the function change. In yeast system, the V336I and R591C mutants of HvHAK1 were revealed to improve $\mathrm{K}^{+}$nutrition and increased $\mathrm{Na}^{+}$tolerance for barley [39]; the L776H and F130S mutants of AtHAK5 improved growth of yeast cells under low- $\mathrm{K}^{+}$and enhanced tolerance to $\mathrm{Na}^{+}$and $\mathrm{Cs}^{+}$in Arabidopsis [40,41]; the R443S, L603H, G606E and R443S of PpH AK1 increased Vmax for $\mathrm{Rb}^{+}$absorption in Physcomitrella patens [42]. As the H. brevisubulatum plants are halophytes and wild species in Hordeum, the evolutionarily adaptive sites of C170 and R342 in conserved domain of HbHAK1 were from natural selection which favored improving $\mathrm{K}$ acquisition to cope with high-salt stresses. Moreover, A13 site was failed in conserved region, but this site was either T13 or N13 in other plants and the changed A13 in HbHAK1was unique. As the A13 site was in $\mathrm{N}$-terminal of HbHAK1, it particularly led to the changes of $\mathrm{Na}^{+}$sensitivity not $\mathrm{Cs}^{+} \mathrm{or} \mathrm{NH}_{4}{ }^{+}$which suggested A13 site may work as external salt reception site. In conclusion, although many key sites 
of HAK-type proteins were explored, our knowledge of core region of $\mathrm{K}^{+}$selectivity, external ion sensing and activity regulation is still fragment. The finding of key naturally selective amino acid sites for HAK1-type protein in $\mathrm{H}$. brevisubulatum provided significant evidence for exploring the structure function studies of HAK-type proteins and indicated the potential value for crop to promote $\mathrm{K}^{+}$uptake under saline conditions.

\section{Materials and Methods}

\subsection{Plant Materials and Growth Condition}

Seeds of H. brevisubulatum in this study used were collected from saline grasslands in Inner Mongolia, China. The methods of the hydroponic culture of the seedlings were described previously [26].

Seeds of Arabidopsis athak5 stored in lab [27] and Columbia (Col-0) were plated on MP (Medium lacking Potassium using for plant culture) medium with $0.5 \%$ sucrose and $0.8 \%$ agar for a week at $21-22{ }^{\circ} \mathrm{C}$ with a $16 \mathrm{~h} / 8 \mathrm{~h}$ (day/night) photoperiod and $60-70 \%$ relative humidity.

\subsection{Isolation of HAK/KUP/KT Family Genes from H. brevisubulatum Transcriptomic Database}

Total RNA was isolated from the root of H. brevisubulatum and H. vulgare via an RNAprep Pure Plant Kit (Tiangen Biotech Co., Ltd., Beijing China). Deep sequencing was performed by Beijing Ori-Gene Science and Technology Corp., Ltd. (Beijing, PR China). The transcriptome library construction and sequencing data analysis was described in previous research [26]. The raw RNA-seq read data was deposited in http://www.ncbi.nlm.nih.gov/sra/; the accession number is SRP161471.

Protein sequences of HAK/KUP/KT family genes in Oryza sativa were obtained from the NCBI website. These sequences were used as a BLAST query in the transcriptomic data to identify putative homologs. $13 \mathrm{HAK} / \mathrm{KUP} / \mathrm{KT}$ proteins with full length of CDS were obtained and their expression data were also extracted. A phylogenetic tree was constructed in MEGA5.0 software (http://www. megasoftware.net/) using protein sequences of these 13 genes and 27 protein sequences of HAK/KUP/KT family in Oryza sativa. The protein sequences of $13 \mathrm{HAK} / \mathrm{KUP} / \mathrm{KT}$ transporters were list in Figure S3.

\subsection{HbHAK1 Expression Transgenic Lines in Arabidopsis athak5}

$\mathrm{HbHAK1}$ was constructed into the vector pBASTA, with green fluorescent protein (GFP) expression driven by the CaMV $35 S$ promoter present in the parent plasmid pBI121 [43] using gateway technology, and then transformed into Arabidopsis athak5 plants using the floral dip method. Transgenic T2 seeds were used for the phenotype analysis. Seeds from the wild type, athak 5 and two different transgenic lines overexpressing HbHAK1 on an athak5 background (HbHAK1-1 and HbHAK1-2) were planted in a seed germination pouch with liquid MP medium containing different concentrations of potassium chloride $(\mathrm{KCl})$ [44]. The Seed germination pouches were placed vertically and photographed after 6 days.

\subsection{Subcellular Localization of HbHAK1}

The cDNA sequences of $H b H A K 1$ overexpression transgenic T1 generation seeds of athak 5 were germinated and grown for 4 days at $21-22^{\circ} \mathrm{C}$ under dark condition. The leaf epidermal cells of the etiolated seedlings were used for microscopic observation. FM4-64 was used to stain the cell plasma membrane. These 4-day seedlings were immersed in $20 \mu \mathrm{g} / \mathrm{mL}$ FM4-64 buffer for $1 \mathrm{~min}$ and then washed with water twice. Confocal images were captured using confocal macroscope equipment (Zeiss, Jena, Germany). The fluorescence signals were excited at $488 \mathrm{~nm}$ for GFP and 561 for the FM4-64 dye.

\subsection{Complementation of HbHAK1 in Cy162 Yeast Strains}

HbHAK1 and HbHAK2 were amplified with special primers and digested with the SpeI/XhoI or EcorI/XhoI restriction enzymes, respectively, and ligated into the yeast expression vector p424 [45]. P424, 
p424-HbHAK1, p424-HbHAK2, p424-HvHAK1, p424-AtHAK5, and p424-OsHAK1 were transformed into yeast (Saccharomyces cerevisiae) strain CY162 trk1 $\triangle \operatorname{trk} 2 \triangle$ [28] and B31 ena1-4 $\triangle$ nha1 $\triangle$ [46]. The primers used was listed in Supplemental Table S1.

Yeast complementation assays at low $\mathrm{K}^{+}$were performed in solid AP-T (Arginine Phosphate medium lacking Trp) medium, as described previously [39] and supplemented with concentrations of $\mathrm{K}^{+}$ranging from 0.001 to $10 \mathrm{mM}$, and in the absence or presence of various concentrations of $\mathrm{NaCl}$ (50 to $750 \mathrm{mM}$ ). For the growth curve, the yeast strains (transformed with p424, p424-HbHAK1 and p424-HbHAK2) were grown in liquid SD-T (minimal Synthetic Defined base with -Trp dropout supplement) medium at $30^{\circ} \mathrm{C}$ overnight and then transferred to liquid AP-T medium supplemented with different concentration of $\mathrm{K}^{+}(0.05$ or $2 \mathrm{mM})$ with the same initial $\mathrm{OD}_{600}$ of about 0.1 . The shaker was adjusted to $200 \mathrm{rpm}$, and the $\mathrm{OD}_{600}$ of the strains was measured every $3 \mathrm{~h}$ for three consecutive days of growth. This experiment was repeated in triplicate.

\section{6. $\mathrm{K}^{+}$Depletion and Measurement of $\mathrm{K}^{+}$Contents in Cy162 Yeast Strains}

For $\mathrm{K}^{+}$depletion experiments, yeast cells were grown overnight at $30^{\circ} \mathrm{C}$ in liquid SD-T medium and then then transferred to liquid AP-T medium for about $4 \mathrm{~h}$ for $\mathrm{K}$ starvation. The cells were then suspended in $10 \mathrm{mM}$ 2-(N-morpholino) ethane sulfonic acid (MES) supplemented with $2 \%$ glucose and adjusted to $\mathrm{pH} 6$ with $\mathrm{Ca}(\mathrm{OH})_{2}$. At time zero, $0.03 \mathrm{mM} \mathrm{KCl}$ were added to the medium and the samples were collected at intervals over a 2 -h period. $\mathrm{K}^{+}$contents were identified and quantified by atomic emission spectrophotometry using a PerkinElmer Model 2380 spectrophotometer (Waltham Mass, US) [47].

\subsection{Site-Directed Mutagenesis of HbHAK1}

For the changes, the different amino acids of HbHAK1 with HvHAK1, we mutated 15 amino acid residues of HbHAK1 according to the right sequence of HvHAK1 by using the Quick change method with site-directed mutagenesis kit (TransGen Biotech, Beijing, China). The protocol was followed as recommended. The primers used was listed in Supplemental Table S1.

\subsection{Accession Numbers}

The selected 13 genes for the HAK/KUP/KT in $H$. brevisubulatum were exhibited in Figure S3. The gene IDs of coordinate genes in $H$. vulgare can be found in the http: //plants.ensembl.org/Hordeum_vulgare/Info/Index, as HvHAK1 (HORVU2Hr1G071570), HvHAK2 (HORVU2Hr1G020220), HvHAK7 (HORVU3Hr1G098670), HvHAK9(HORVU2Hr1G018190), HvHAK11 (HORVU2Hr1G098940), HvHAK15 (HORVU2Hr1G099810), HvHAK18 (HORVU5Hr1G090010), HvHAK23 (HORVU5Hr1G059200) and HvHAK25(HORVU6Hr1G073030).

Supplementary Materials: Supplementary materials can be found at http://www.mdpi.com/1422-0067/21/15/5292/s1. Figure S1 The growth of B31 strains transformed with the empty vector p424 (EV), p424-HbHAK1 (HbHAK1) or p424-AtHAK5 (AtHAK5) in solid AP-T medium without or with $50 \mathrm{mM} \mathrm{Na}^{+}$under $10 \mathrm{mM} \mathrm{K}^{+}$condition. Figure S2 The growth of Cy162 strains transformed with WT HbHAK1 and the mutants A13T, C170A and R342K in solid AP-T medium under $5 \mathrm{mM} \mathrm{K}^{+}$concentration with $20 \mathrm{mM} \mathrm{Na}^{+}, 20 \mathrm{mM} \mathrm{Cs}^{+}$or $20 \mathrm{mM} \mathrm{NH}_{4}^{+}$added. Figure S3 Multiple alignment of 13 obtained HAK/KUP/KT proteins. Table S1 The primers used in this paper.

Author Contributions: Conceptualization and experiment design, H.Z. and R.L.; experiments performed by W.X., W.Y., Y.J. and H.Z.; data analysis, H.Z., R.L. and W.X.; writing and editing, H.Z., W.X., and R.L. All authors have read and agreed to the published version of the manuscript.

Funding: This work was supported by the Special Program for Innovation of Beijing Academy of Agriculture and Forestry Sciences with grants to H.Z. (KJCX20180412), the Natural Science Foundation of Beijing Municipality with grant to H.Z. (5182007), the Science and Technology Development Center of the National Forestry and Grassland Administration with Grant to R; (L) (KJZXSA202028) and the Special Program for Innovation of Beijing Academy of Agriculture and Forestry Sciences with grants to R.L. (JKZX201901).

Acknowledgments: We thank Begoña Benito (Madrid, Spain) and Hyeong Cheol Park (Korea) for kindly providing the yeast mutant strains and vectors. 
Conflicts of Interest: The authors declare that they have no conflict of interest.

\section{References}

1. Srivastava, A.K.; Shankar, A.; Nalini Chandran, A.K.; Sharma, M.; Jung, K.H.; Suprasanna, P.; Pandey, G.K. Emerging concepts of potassium homeostasis in plants. J. Exp. Bot. 2020, 71, 608-619. [CrossRef]

2. Shabala, S.; Pottosin, I. Regulation of potassium transport in plants under hostile conditions: Implications for abiotic and biotic stress tolerance. Physiol. Plant 2014, 151, 257-279. [CrossRef] [PubMed]

3. Shabala, S. Signalling by potassium: Another second messenger to add to the list? J. Exp. Bot. 2017, 68, 4003-4007. [CrossRef]

4. Li, W.; Xu, G.; Alli, A.; Yu, L. Plant HAK/KUP/KT K ${ }^{+}$transporters: Function and regulation. Semin. Cell Dev. Biol. 2018, 74, 133-141. [CrossRef] [PubMed]

5. Nieves-Cordones, M.; Ródenas, R.; Chavanieu, A.; Rivero, R.M.; Martinez, V.; Gaillard, I.; Rubio, F. Uneven $\mathrm{HAK} / \mathrm{KUP} / \mathrm{KT}$ protein diversity among angiosperms: Species distribution and perspectives. Front. Plant Sci. 2016, 7, 127. [CrossRef] [PubMed]

6. Gierth, M.; Mäser, P.; Schroeder, J.I. The potassium transporter AtHAK5 functions in $\mathrm{K}^{+}$deprivation-induced high-affinity $\mathrm{K}^{+}$uptake and $\mathrm{AKT} 1 \mathrm{~K}^{+}$channel contribution to $\mathrm{K}^{+}$uptake kinetics in Arabidopsis roots. Plant Physiol. 2005, 137, 1105-1114. [CrossRef]

7. Santa-María, G.E.; Rubio, F.; Dubcovsky, J.; Rodríguez-Navarro, A. The HAK1 gene of barley is a member of a large gene family and encodes a high-affinity potassium transporter. Plant Cell 1997, 177, 2281-2289.

8. Chen, G.; Hu, Q.; Luo, L.; Yang, T.; Zhang, S.; Hu, Y.; Yu, L.; Xu, G. Rice potassium transporter OsHAK1 is essential for maintaining potassium-mediated growth and functions in salt tolerance over low and high potassium concentration ranges. Plant Cell Environ. 2015, 38, 2747-2765. [CrossRef]

9. Yang, T.; Zhang, S.; Hu, Y.; Wu, F.; Hu, Q.; Chen, G.; Cai, J.; Wu, T.; Moran, N.; Yu, L.; et al. The role of a potassium transporter OsHAK5 in potassium acquisition and transport from roots to shoots in rice at low potassium supply levels. Plant Physiol. 2014, 166, 945-959. [CrossRef]

10. Alemán, F.; Nieves-Cordones, M.; Martínez, V.; Rubio, F. Differential regulation of the HAK5 genes encoding the high-affinity $\mathrm{K}^{+}$transporters of Thellungiella halophila and Arabidopsis thaliana. Environ. Exp. Bot. 2009, 65, 263-265. [CrossRef]

11. Nieves-Cordones, M.; Martínez-Cordero, M.A.; Martínez, V.; Rubio, F. An $\mathrm{NH}_{4}{ }^{+}$sensitive component dominates high-affinity $\mathrm{K}^{+}$uptake in tomato plants. Plant Sci. 2007, 172, 273-280. [CrossRef]

12. Ruiz-Lau, N.; Bojórquez-Quintal, E.; Benito, B.; Echevarría-Machado, I.; Sánchez-Cach, L.A.; Medina-Lara, M.F.; Martínez-Estévez, M. Molecular cloning and functional analysis of a $\mathrm{Na}^{+}$-insensitive $\mathrm{K}^{+}$ transporter of Capsicum chinense Jacq. Front. Plant Sci. 2016, 7, 1980. [CrossRef] [PubMed]

13. Shabala, S.; Demidchik, V.; Shabala, L.; Cuin, T.; Smith, S.J.; Miller, A.J.; Davies, J.M.; Newman, I.A. Extracellular $\mathrm{Ca}^{2+}$ ameliorates $\mathrm{NaCl}$-induced $\mathrm{K}^{+}$loss from Arabidopsis root and leaf cells by controlling plasma membrane $\mathrm{K}^{+}$-permeable channels. Plant Physiol. 2006, 1, 1653-1665. [CrossRef] [PubMed]

14. Carden, D.E.; Walker, D.J.; Flowers, T.J.; Miller, A.J. Single-cell measurements of the contributions of cytosolic $\mathrm{Na}^{+}$and $\mathrm{K}^{+}$to Salt Tolerance. Plant Physiol. 2003, 131, 676-683. [CrossRef]

15. Adams, E.; Abdollahi, P.; Shin, R. Cesium inhibits plant growth through jasmonate signaling in Arabidopsis thaliana. Int. J. Mol. Sci. 2013, 14, 4545-4559. [CrossRef]

16. Shabala, S.; Cuin, T. Potassium transport and plant salt tolerance. Physiol. Plant 2008, 133, 651-669. [CrossRef]

17. Rubio, F.; Nieves-Cordones, M.; Horie, T.; Shabala, S. Doing 'business as usual' comes with a cost: Evaluating energy cost of maintaining plant intracellular $\mathrm{K}^{+}$homeostasis under saline conditions. New Phytol. 2020, 225, 1097-1104. [CrossRef]

18. Chen, G.; Liu, C.; Gao, Z.; Zhang, Y.; Jiang, H.; Zhu, L.; Ren, D.; Yu, L.; Xu, G.; Qian, Q. OsHAK1, a High-Affinity potassium transporter, positively regulates responses to drought stress in rice. Front. Plant Sci. 2017, 8, 1885. [CrossRef]

19. Shen, Y.; Shen, L.; Shen, Z.; Jing, W.; Ge, H.; Zhao, J. The potassium transporter OsHAK21 functions in the maintenance of ion homeostasis and tolerance to salt stress in rice. Plant Cell Environ. 2015, 38, 2766-2779. [CrossRef]

20. Zhang, M.; Liang, X.; Wang, L.; Cao, Y.; Song, W.; Shi, J.; Lai, J.; Jiang, C. A HAK family Na ${ }^{+}$transporter confers natural variation of salt tolerance in maize. Nat. Plants 2019, 5, 1297-1308. [CrossRef] 
21. Fita, A.; Rodríguez-Burruezo, A.; Boscaiu, M.; Prohens, J.; Vicente, O. Breeding and domesticating crops adapted to drought and salinity: A new paradigm for increasing food production. Front. Plant Sci. 2015, 6, 978. [CrossRef] [PubMed]

22. Mano, Y.; Takeda, K. Genetic resources of salt tolerance in wild Hordeum species. Euphytica 1998, 103, 137-141. [CrossRef]

23. Brassac, J.; Blattner, F.R. Species-Level Phylogeny and Polyploid Relationships in Hordeum (Poaceae) Inferred by Next-Generation Sequencing and In Silico Cloning of Multiple Nuclear Loci. Syst. Biol. 2015, 64, 792-808. [CrossRef] [PubMed]

24. Li, R.F.; Zhang, J.W.; Wu, G.Y.; Wang, H.Z.; Chen, Y.J.; Wei, J.H. HbCIPK2, a novel CBL-interacting protein kinase from halophyte Hordeum brevisubulatum, confers salt and osmotic stress tolerance. Plant Cell Environ. 2012, 35, 1582-1600. [CrossRef]

25. Wang, C.M.; Xia, Z.R.; Wu, G.Q.; Yuan, H.J.; Wang, X.R.; Li, J.H.; Tian, F.P.; Zhang, Q.; Zhu, X.Q.; He, J.J.; et al. The coordinated regulation of $\mathrm{Na}^{+}$and $\mathrm{K}^{+}$in Hordeum brevisubulatum responding to time of salt stress. Plant Sci. 2016, 252, 358-366. [CrossRef]

26. Zhang, H.W.; Feng, H.; Zhang, J.W.; Ge, R.C.; Zhang, L.L.; Wang, Y.X.; Li, L.G.; Wei, J.H.; Li, R.F. Emerging crosstalk between two signaling pathways coordinates $\mathrm{K}^{+}$and $\mathrm{Na}^{+}$homeostasis in the halophyte Hordeum brevisubulatum. J. Exp. Bot. 2020. [CrossRef] [PubMed]

27. Rubio, F.; Nieves-Cordones, M.; Alemán, F.; Martínez, V. Relative contribution of AtHAK5 and AtAKT1 to $\mathrm{K}^{+}$uptake in the high-affinity range of concentrations. Physiol. Plant 2008, 134, 598-608. [CrossRef]

28. Anderson, J.A.; Huprikar, S.S.; Kochian, L.V.; Lucas, W.J.; Gaber, R.F. Functional expression of a probable Arabidopsis thaliana potassium channel in Saccharomyces cerevisiae. Proc. Natl. Acad. Sci. USA 1992, 89, 3736-3740. [CrossRef]

29. White, P. Improving potassium acquisition and utilisation by crop plants. J. Plant Nutr. Soil Sci. 2013, 176, 305-316. [CrossRef]

30. Sentenac, H.; Bonneaud, N.; Minet, M.; Lacroute, F.; Salmon, J.M.; Gaymard, F.; Grignon, C. Cloning and expression in yeast of a plant potassium-ion transport-system. Science 1992, 256, 663-665. [CrossRef]

31. Nieves-Cordones, M.; Alemán, F.; Martínez, V.; Rubio, F. The Arabidopsis thaliana $\mathrm{HAK} 5 \mathrm{~K}^{+}$transporter is required for plant growth and $\mathrm{K}^{+}$acquisition from low $\mathrm{K}^{+}$solutions under saline conditions. Mol. Plant 2010, 3, 326-333. [CrossRef] [PubMed]

32. Zhang, L.L.; Wang, Y.X.; Zhang, Q.K.; Jiang, Y.; Zhang, H.W.; Li, R.F. Overexpression of HbMBF1a, encoding multiprotein bridging factor 1 from the halophyte Hordeum brevisubulatum, confers salinity tolerance and ABA insensitivity to transgenic Arabidopsis thaliana. Plant Mol. Biol. 2020, 102, 1-17. [CrossRef] [PubMed]

33. Okada, T.; Yamane, S.; Yamaguchi, M.; Kato, K.; Shinmyo, A.; Tsunemitsu, Y.; Iwasaki, K.; Ueno, D.; Demura, T. Characterization of rice KT/HAK/KUP potassium transporters and $\mathrm{K}^{+}$uptake by HAK1 from Oryza sativa. Plant Biotechnol. 2018, 35, 101-111. [CrossRef]

34. Martínez-Cordero, M.A.; Martínez, V.; Rubio, F. Cloning and functional characterization of the high-affinity $\mathrm{K}^{+}$transporter HAK1 of pepper. Plant Mol. Biol. 2004, 56, 413-421. [CrossRef]

35. Mackinnon, R. Potassium channels. FEBS Lett. 2003, 555, 62-65. [CrossRef]

36. Dreyer, I.; Uozumi, N. Potassium channels in plant cells. FEBS J. 2011, 278, 4293-4303. [CrossRef]

37. Benito, B.; Haro, R.; Amtmann, A.; Cuin, T.A.; Dreyer, I. The twins $\mathrm{K}^{+}$and $\mathrm{Na}^{+}$in plants. J. Plant Physiol. 2014, 171, 723-731. [CrossRef]

38. Corratgé-Faillie, C.; Jabnoune, M.; Zimmermann, S.; Véry, A.; Fizames, C.; Sentenac, H. Potassium and sodium transport in Non-Animal cells: The Trk/Ktr/HKT Transporter Family. Cell. Mol. Life Sci. 2010, 67, 2511-2532. [CrossRef]

39. Mangano, S.; Silberstein, S.; Santa-María, G.E. Point mutations in the Barley HvHAK1 potassium transporter lead to improved $\mathrm{K}^{+}$-nutrition and enhanced resistance to salt stress. FEBS Lett. 2008, 582, 3922-3928. [CrossRef]

40. Rubio, F.; Santa-Maria, G.E.; Rodrigues-Navarro, A. Cloning of Arabidopsis and barley cDNAs encoding HAK potassium transporters in root and shoot cells. Physiol. Plant 2000, 109, 34-43. [CrossRef]

41. Alemán, F.; Caballero, F.; Ródenas, R.; Rivero, R.M.; Martínez, V.; Rubio, F. The F130S point mutation in the Arabidopsis high-affinity $\mathrm{K}^{+}$transporter AtHAK5 increases $\mathrm{K}^{+}$over $\mathrm{Na}^{+}$and $\mathrm{Cs}^{+}$selectivity and confers $\mathrm{Na}^{+}$and $\mathrm{Cs}^{+}$tolerance to yeast under heterologous expression. Front. Plant Sci. 2014, 5, 430. [CrossRef] [PubMed] 
42. Garciadeblas, B.; Barrero-Gil, J.; Benito, B.; Rodríguez-Navarro, A. Potassium transport systems in the moss Physcomitrella Patens: pphak1 plants reveal the complexity of potassium uptake. Plant J. 2007, 52, 1080-1093. [CrossRef] [PubMed]

43. Cutler, S.R.; Ehrhardt, D.W.; Griffitts, J.S.; Somerville, C.R. Random GFP::cDNA fusions enable visualization of subcellular structures in cells of Arabidopsis at a high frequency. Proc. Natl. Acad. Sci. USA 2000, 97, 3718-3723. [CrossRef] [PubMed]

44. Hirsch, R.E.; Lewis, B.D.; Spalding, E.P.; Sussman, M.R. A role for the AKT1 potassium channel in plant nutrition. Science 1998, 280, 918-921. [CrossRef]

45. Brunelli, J.P.; Pall, M.L. A series of yeast/Escherichia coli lambda expression vectors designed for directional cloning of cDNAs and cre/lox-mediated plasmid excision. Yeast 1993, 9, 1309-1318. [CrossRef]

46. Bañuelos, M.A.; Garciadeblas, B.; Cubero, B.; Rodríguez-Navarro, A. Inventory and functional characterization of the HAK potassium transporters of rice. Plant Physiol. 2002, 130, 784-795. [CrossRef]

47. Fraile-Escanciano, A.; Kamisugi, Y.; Cuming, A.C.; Rodríguez-Navarro, A.; Benito, B. The SOS1 transporter of Physcomitrella patens mediates sodium efflux in planta. New Phytol. 2010, 188, 750-761. [CrossRef]

(C) 2020 by the authors. Licensee MDPI, Basel, Switzerland. This article is an open access article distributed under the terms and conditions of the Creative Commons Attribution (CC BY) license (http://creativecommons.org/licenses/by/4.0/). 